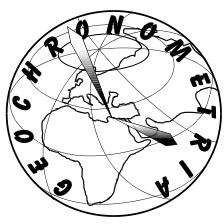

Conference Proceedings of the $4^{\text {th }}$ Asia Pacific Luminescence and Electron Spin Resonance Dating Conference Nov $23^{\text {rd }}-25^{\text {th }}, 2015$, Adelaide, Australia

Guest Editor: Jon Olley

\title{
KOONALDA CAVE, NULLARBOR PLAIN, SOUTH AUSTRALIA - ISSUES IN OPTICAL AND RADIOMETRIC DATING OF DEEP KARST CAVES
}

\author{
KERYN WALSHE \\ Department of Anthropology, South Australia Museum, Adelaide, South Australia, Australia
}

Received 14 March 2016

Accepted 21 September 2017

\begin{abstract}
Koonalda Cave is located on the Nullarbor Plain of South Australia and is one of 17 deep karst caves in this region. In 2014, the cave was listed as a National Heritage Place in recognition of its significant archaeological and cultural heritage features. It In order to understand the antiquity of and complex human activity in this site a range of dating methods have been applied including typologic, radiometric and luminescence. Each has been challenged and the chronology of this highly significant site has relied on contextual data from other sites. This paper presents an overview of the archaeology recorded at Koonalda Cave, the issues in dating sites in deep karst systems and emphasises the urgent need to resolve these issues so that a reliable chronology can be presented for Koonalda Cave.
\end{abstract}

Keywords: Koonalda Cave, Allen's Cave, Nullarbor, dating techniques, Gallus excavation.

\section{INTRODUCTION}

Koonalda Cave is a deep karst cave located on the Nullarbor Plain of South Australia (Fig. 1 and Fig. 2). In 2014 it gained National Heritage Listing due to its highly significant cultural heritage values (Commonwealth of Australia, 2014).

Koonalda Cave is a series of large vault like chambers connected by hundreds of meters of passages varying from cavernous to extremely narrow (Fig. 3). The entrance to the cave is accessed by descending into collapsed doline and the cave floor is reached after a steep descent over boulders. The cave floor is approximately $75 \mathrm{~m}$ below ground surface and from here two main pas-

Corresponding author: K. Walshe e-mail: kerynw@internode.on.net sages branch off to the north and the northwest (Fig. 3). The former offers virtually no archaeological evidence but does contain large lakes whilst the latter contains significant archaeology and has evidence for a former lake (Fig. 3). Flint is recognised by the protrusion of large nodules occurring in distinct bands that are visible high above and down to floor level.

Archaeological research was initiated by Dr Alexander Gallus in 1958 following an earlier speleological report of possible evidence for Aboriginal occupation (Pretty, 1960). Gallus continued his investigations into the 1980s but since that time both interest and funding to continue the research have been infrequent.

Although the Nullarbor Plain is characteristically flat, arid and treeless, the archaeology indicates that humans were present by at least 35,000 years ago (Roberts et al., 1996 and Smith, 2013). This time span includes the Last Glacial Maximum (LGM) which held the sea some 150 


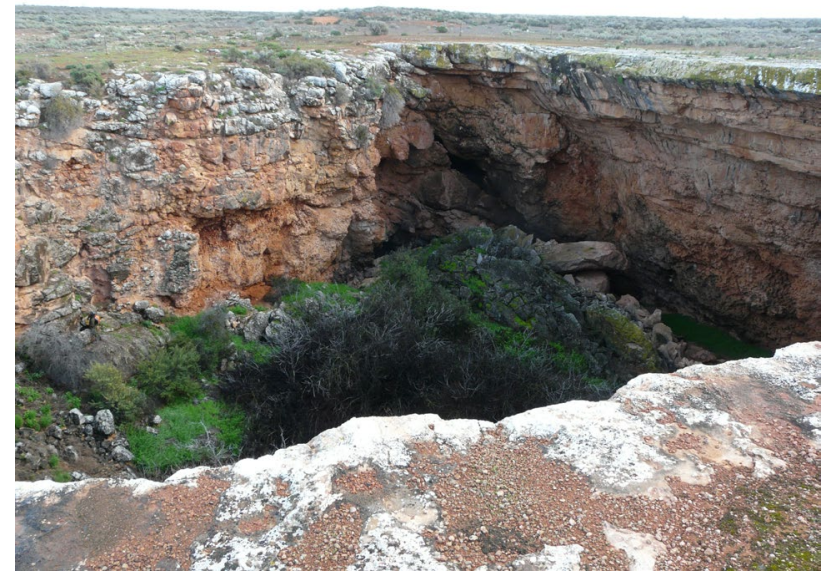

Fig. 1. Koonalda Cave - collapsed doline on flat surface of Nullabor Plain.

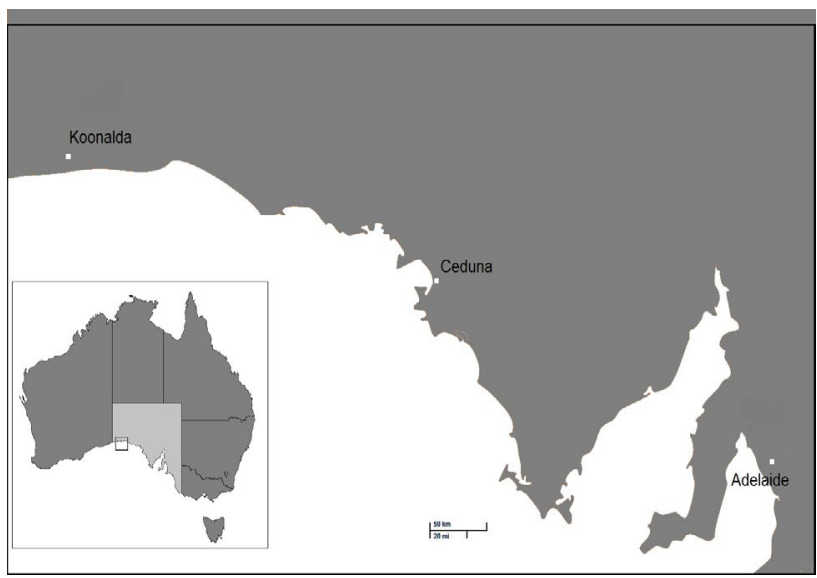

Fig. 2. Location of Koonalda Cave, South Australia.

$200 \mathrm{~km}$ further to the south of the Plain and consequent particularly inhospitable conditions. The LGM commenced some 25,000 years ago and continued across approximately 10,000 years before amelioration set in (Smith, 2013). Despite the changing environmental and climatic conditions, Koonalda Cave continued to be visited by humans before, during and after the LGM. It is only Koonalda Cave and nearby Allen's Cave (approximately $80 \mathrm{~km}$ west of Koonalda cave) that have provided evidence for on-going visitation during the LGM (Walshe, 2012; Cane, 2013 and Smith, 2013).

Early archaeological investigations recorded parietal art and flint 'mining' which sparked enormous public interest both nationally and internationally (Gallus, 1968a and 1968b and Flood, 1997). The term 'mining' is deceptive in view of far stronger evidence for Indigenous people using flint that has naturally fallen from the cave walls, rather than using digging tools to excavate it from the walls. The use of the term 'mining' has been used rather uncritically in Australian archaeology and can be misleading when comparing with reports of prehistoric mining in Europe, for example. This complex but worthy discussion is not critical to the focus of this paper and will be pursued elsewhere.

Dissent over the age of the site and its particular archaeological features arose soon after investigations commenced (Wright, 1971; Flood, 1997; Gillespie, 2002 and Bednarik et al., 2003). Despite applying different methodologies over time, the difficulty of providing reliable dating for Koonalda continues to provide a significant challenge for the interpretation of Aboriginal presence in the site. In turn this has prevented a reliable chronology for the sedimentology, physical formation and palaeoenvironment of the cave (Jennings, 1961; Wright, 1971 and Gillespie, 2002).

\section{SAMPLING HISTORY}

Gallus dug three archaeological trenches into the main chamber of the northwest passage between 1960 and 1973 (Gallus, 1968a; 1971 and 1973). Extensions to the third trench were dug by Richard Wright in 1967 in response to questions over the reliability of the radiometric results produced earlier by Gallus (Wright, 1971). Trench 111 offered the most comprehensive assemblage and extensive profile. Unfortunately, the depths and descriptions of each horizon or layer displayed in Trench 111 lacks consistency across the individual reports by Wright and Gallus (Wright, 1971). As it is the stratigraphic profile drawn by Shirley Jago and presented by Gallus in Wright (1971:89) that has been the focus of numerous subsequent reports, it is this profile which is reproduced here as Fig. 4.

Trench 111 was excavated to below $4 \mathrm{~m}$ and displays two distinct horizons consisting of essentially an upper white horizon some $2 \mathrm{~m}$ thick and a lower red horizon of approximately $4 \mathrm{~m}$ thickness in total (it was not excavated to bedrock). A very narrow intermediate band between the two very distinct horizons was described as rosa tinted limestone dust (Jennings, 1961; Galllus, 1968a and 1968b and Frank, 1971).

The upper white horizon was described by Gallus as 'plastic white' limestone in varying phases of cementation, slumped against the cave wall. The plastic white is free of roof fall but contains wall fall. This horizon contained an assemblage of worked flint in an otherwise sterile layer (Fig. 4). The presence of this single assemblage suggests that either human visitation was occurring infrequently or the wall fall occurred rapidly between regular visits. Frequency of visitation may have been influenced by availability of light but this will also be pursued elsewhere, similarly to the term 'mining'.

Onto the sloping surface of this plastic white are uneven layers of large roof fall, clusters and bands of dense charcoal and spalled and worked flint. These are generally layered horizontally but of differing lengths due to the angle of slope caused by the slump of wall fretted material. 


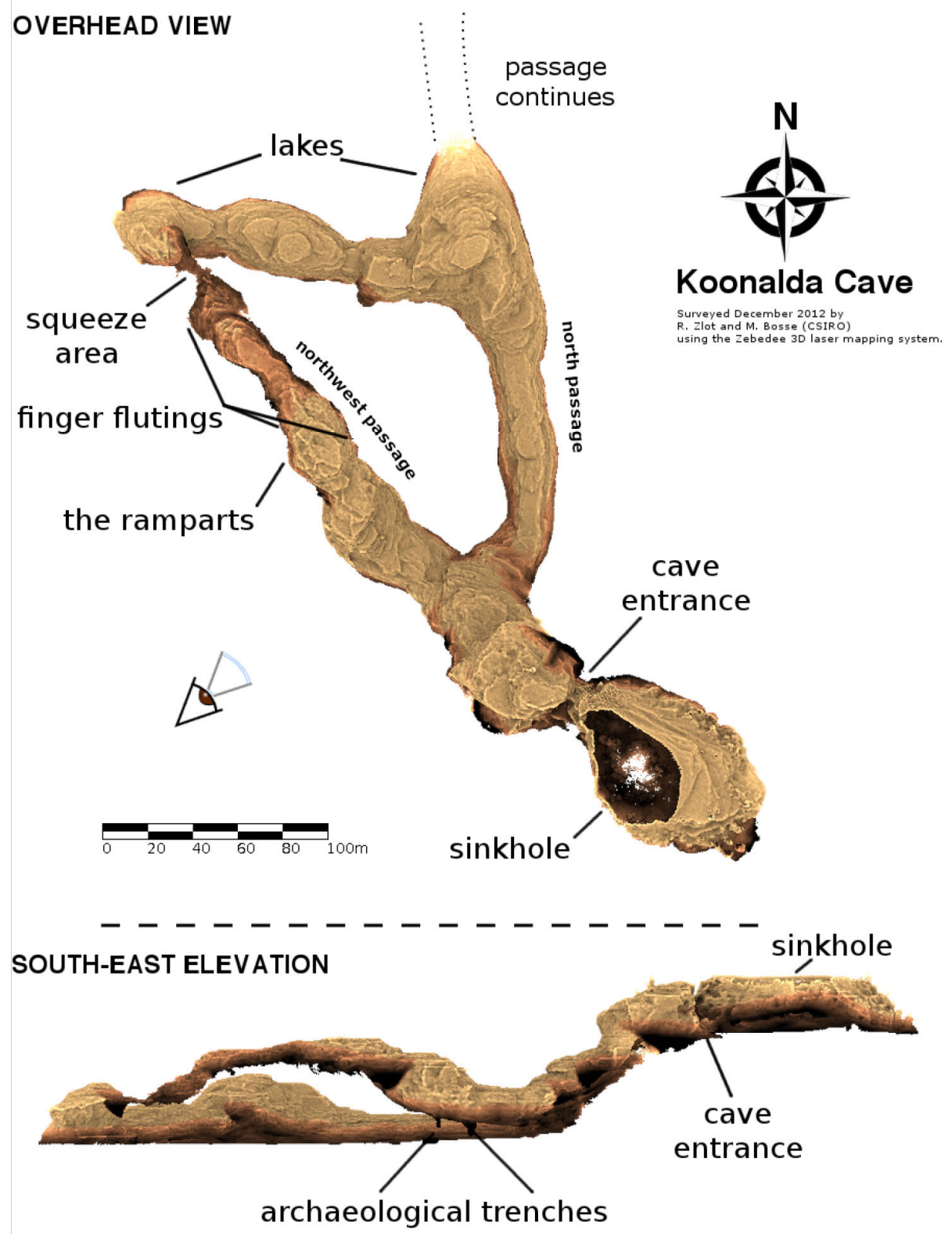

Fig. 3. 3D representation of Koonalda Cave (Zlot and Bosse 2014:202).

The lower red horizon consists of horizontally bedded sands, silts and clays eroded from the Nullarbor Plain and some spalled limestone detritus (Jennings, 1961 and Frank, 1971). Its matrix reflects a lacustrine depositional environment that once existed in this part of the cave. The shift from the lower red to the upper (plastic) white horizon was suggested by Frank (1971) to reflect the diversion of stream flow from this part of the cave floor to the north passage (Frank, 1971). This red horizon contains virtually no spalled flint and only one small assemblage of culturally worked flint in association with a bone tool and some discarded animal bone (Floor 7 in Fig. 4). The presence of such minimal archaeology throughout the red horizon is difficult to interpret. If the lake was filled during times of human visitation, then logically people will settle around its margins but the excavation may have been well within the lacustrine zone. Furthermore, the lacustrine conditions themselves were presumably episodic, following seasonal rainfall or cyclonic events. The strength and velocity of the sudden stream flow will also have varied but would have generally disaggregated an assemblage into a number of parts, dispersed around the 


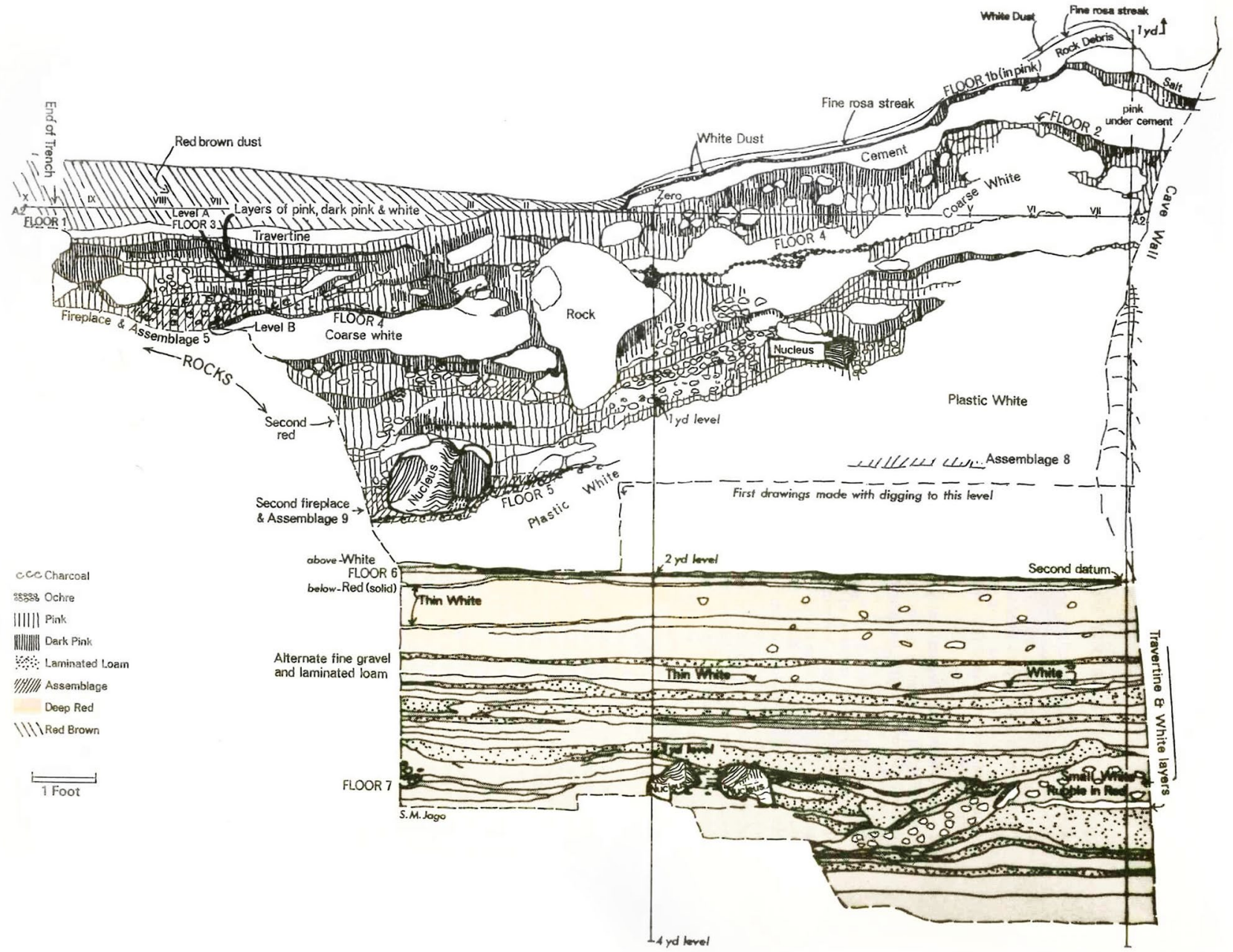

Fig. 4. Stratigraphy of Koonalda Cave (adapted from Gallus 1971:89 in RVS Wright (ed) Archaeology of the Gallus Site).

cave floor. Another critical factor is the fall of natural light onto the cave floor and creating a highly favourable place for humans to occupy. In all, it may be that the red horizon reflects an internally stable environment but one with sudden, variable stream flow leading to some degree of displacement of cultural evidence and the relocation of preferred working areas to drier ground. Changes in the fall of natural light seasonally and climatically will also affect this final choice. The excavation trenches were invariably placed against a wall of the cave in convention with European archaeological excavations in caves. The influencing factors discussed above, such as daylight and stream flow, on making the choice for the 'best spot' to sit and work flint on any one occasion did not determine where excavations were undertaken.

Although minimal against the vast quantity of material excavated from Koonalda Cave, the presence of a cultural floor (flint workshop) near the base of the red horizon is still of immense importance as it provides the ear- liest physical evidence for human presence in the Cave. The dating of this material and/or the red horizon may offer a clearer chronological context for the lake in the north-west passage and also for the parietal art.

\section{DATING}

Prior to availability of radiometric analysis, Gallus attempted to establish a chronological framework for Koonalda based on subtle changes in the rosa coloured limestone dust; typology of the parietal art and the stratigraphy and formation of the cave (Gallus, 1966, 1968a and 1968b). By applying his experience gained from working in caves in Europe prior to arriving in Australia post World War II, Gallus hypothesised that humidity altered the colour and hue of the limestone dust which encouraged his particularity in establishing a system to record the rosa layers as light, medium or dark. He then identified four cycles of climatic events affecting the cave 
between 40,000 and 10,000 years ago and also noted sheets of travertine that had 'formed under shallow surface of standing water in depressions of rockfalls'. By drawing on his knowledge of palaeolithic and mousterian caves in Europe (using these terms as a type rather than a culture) and his knowledge of Wurm interstadials, Gallus hypothesised that the upper white layer of the profile was dated to post LGM and the lower red, particularly below Floor 7, accumulated during the LGM. He also postulated that the sediments above Floor 1, represented the transition of the Nullarbor Plain into later Holocene conditions. He saw this point in time as the moment when Indigenous people no longer included the Plain and its caves in their sphere of ecological knowledge (Pretty and Gallus, 1967). In summary, he speculated that Koonalda was occupied well before 30,000 years ago, used intensively between 20,000 and 10,000, after which visitation dwindled away and abandoned around 5-6,000 years ago (Gallus, 1966, 1968a, 1968b and 1971).

Later research by Christine Sharpe and Kevin Sharpe (2003) also attempted to construct a chronology with typology at its core. Their individual and combined research strove to establish a classificatory system based on observed stages of weathering on roof fall boulders (Sharpe and Fawbert, 2000 and Sharpe, 2008). Such systems are however fraught when working in taphonomically dynamic environments that have been built by multiple and changing agents over long periods of time (Lee Lyman, 1994).

\section{RADIOMETRIC 1960-1990}

The first radiometric analyses for Koonalda cave were on charcoal samples taken from archaeological excavations in the 1960-70s. No conventional cooking hearths have been identified in the excavation profiles and this is supported by the lack of food remains in the assemblages. Despite this, there is are deposits of charcoal throughout the profile which Gallus believed to have been derived from the lighting of fire brands or torches in order to generate sufficient light for working flint inside the cave (Gallus, 1971).

The carbon 14 results published by Gallus (1968b and 1971) reveal a range of 13,700 to $31,000 \mathrm{BP}$. Wright also submitted samples from a trench adjacent to Gallus's Trench 111 and gained a range of 16,000 to $24,000 \mathrm{BP}$ (Wright, 1971). Whilst the upper date obtained by each archaeologist is reasonably similar, the lower dates are significantly different and problematically, these lower dates were not derived from the same horizon. Gallus's 31,000 BP date came from the upper white horizon whilst Wright's date of 24,000 BP came from the bottom of the red level. Gallus argued for permeability of carbon upwards through loosely packed rockfall, as water entered the cave and flooded through the excavated areas. He reasoned that this upward movement of carbon particles led to redepositing of samples which in turn inversed the dating. This argument may be plausible but has yet to be tested.

Overall the radiocarbon dates were far from sequential and it was variously argued that the samples were contaminated; the excavations lacked expertise or that micro-permeability operated throughout the sedimentary layers (Wright, 1971 and Gallus n.d., 1968a and 1971). This controversy clouded the research and eventually affected public and institutional interest in the site. Later revisions of radiometric dating from a range of Australian sites have pointed out the inherent problems in the Australian environment, particularly when working close to the carbon boundary (Gillespie, 2002; Bednarik, 1986 and Bednarik et al., 2003).

\section{RECENT RADIOMETRIC RESULTS}

With such discrepancy in the earlier radiometric analyses, a new round of analysis was recently undertaken on existing material held at the South Australia Museum and on samples collected in situ from the profile of Trench 111. From the museum assemblage four samples were selected from the white (upper) horizon of Gallus's Trench 111 excavation. The samples were coded according to Gallus's identifier (Gallus n.d.). Depth for each sample was measured from the stratigraphic profile provided by Gallus (1971:89) (Fig. 4) and are therefore approximate.

Trench 111 excavation was not backfilled and as such continues to provide access to the same profile sampled by Gallus and Wright. In 2013 two new samples were extracted from the intermediate zone between the upper white and the lower red horizons where the charcoal band described by Gallus (1971) is still visible. These were designated KLDA-intermediate zone (a) and (b).

Six samples returned results ranging from approximately 7,780-23,000 BP (Table 1).

As shown in Table 1, the samples represent a span of $192 \mathrm{cms}$ and are reasonably sequential against depth. Furthermore, the recently collected in situ samples (KLDA intermediate zone (a) \& (b)) support Gallus's date of approximately 24,000 BP for the same interface. In turn, this date places the interface of the red and white horizons within the LGM and concomitant with the broad scale drying and increasing aridity across the country. It is unsurprising that stream flow into the north-west passage terminated at this time. The lack of red sediments entering the cave after 24,000 years ago allowed the development of the predominantly upper white horizon. It is unclear if the approximate and equivalent dates of 17,500 for both $132 \mathrm{~cm}$ and $63 \mathrm{~cm}$ below datum suggests accelerated cave fretting and is perhaps due to hyper aridity operating external to the cave. None the less, these dates do confirm the presence of humans in Koonalda Cave during the Pleistocene and across the LGM.

The two upper most samples (C-15-34 and KLDA B4-16, Ass.5.Fl.4) were collected about $55 \mathrm{~cm}$ 
Table 1. KLDA Radiocarbon Samples and Results.

\begin{tabular}{|c|c|c|c|}
\hline Code & $\begin{array}{l}\text { Depth from '0' datum, Trench } 111 \text { (approx. } \\
\text { (cm) }\end{array}$ & $\begin{array}{l}\text { Age }{ }^{14} \mathrm{C} \\
\text { (BP) }\end{array}$ & $\begin{array}{l}\text { Deviation } \\
\text { ( } \pm \text { BP) }\end{array}$ \\
\hline${ }^{*} \mathrm{C}-15-34$ & 10 above & 10,085 & 31 \\
\hline \#KLDA B4-16, Ass.5 Fl.4 & 45 below & 7,787 & 40 \\
\hline${ }^{*} \mathrm{~B} 6-2$, Ass.5 & 63 below & 17,568 & 61 \\
\hline${ }^{*} \mathrm{C}-19-3$ & 132 below & 17,375 & 60 \\
\hline${ }^{*}$ KLDA intermediate zone (a) & 182 below & 23,019 & 92 \\
\hline${ }^{*}$ KLDA intermediate zone (b) & 182 below & 23,040 & 109 \\
\hline
\end{tabular}

* Waikato radiocarbon dating lab; \# Rafter GNS Science.

[The Carbon-13 stable isotope value $\left(\delta^{13} \mathrm{C}\right)$ was measured on prepared graphite using the AMS spectrometer. The radiocarbon date has therefore been corrected for isotopic fractionation. However, the AMS-measured $\delta^{13} \mathrm{C}$ value can differ from the $\delta^{13} \mathrm{C}$ of the original material and it is therefore not shown.]

above/below each other and a reversal in the dates is evident. Gallus (1971) repeatedly referred to the micropermeability of charcoal in the upper white horizon. With ameliorating conditions operating external to the cave, it is possible that the cave fretting slowed down with rejuvenated stream flow heading to the north passage rather than pooling in chamber of the cave and flowing northwest. With such a combination of conditions, it is possible that particles moved through loosely compacted pockets formed between slabs of roof fall and redeposited. However, this remains conjecture until sophisticated sedimentary analysis can be undertaken. Such analysis may also explain the controversial V-82 of $31,000 \pm 1650$ BP reported by Gallus (1971).

Two additional dates were obtained in view of the significance of the association of charcoal with a significant object. A piece of cave wall was excavated by Gallus in Trench F. This piece (measuring approximately $10 \times 15 \times 3 \mathrm{~cm}$ ) displayed finger flutings on one face and was composed of calcium carbonate, matching the famous 'moonmilk' of the finger flutings gallery. Trench $\mathrm{F}$ was placed in the large chamber, some $100 \mathrm{~m}$ southeast of the gallery, clearly indicating that this piece was transported into the main chamber. Avoiding further conjecture on the terminology of 'portable art', charcoal associated with this piece (coded C3-F11 Waikato Lab) yielded a date of $18,123 \pm 59$. This result provides the only minimum date for the parietal art at Koonalda Cave.

Post cranial osteology material identified as Canis familiaris (dingo) was collected from the surface of Trench 111 during the original excavation by Gallus. Radiometric analysis of the bone returned a result of $3031 \pm 34$ (OxA-27532). The date fits well within the spectrum of published dates for the arrival of the dingo into southern Australia (Smith, 2015). Numerous dingo skeletons have been observed in Koonalda Cave over the years of exploration. These unfortunate animals appear to have been unable to escape and died from natural mortality. The 3,000 year old dingo may well have suffered a similar fate although it may equally well have followed humans into the site.

\section{LUMINESCENCE 1990s}

Obtaining reliable dating has long been one of the most challenging aspects of archaeology globally. With the introduction of luminescence dating techniques it was hoped that the problems of vertical displacement and/or contamination of charcoal could be overcome. However, this methodology is equally challenged by very low dose rates and incomplete and inconsistent bleaching of ancient sediments (Roberts et al., 1995, 1996 and Gillespie, 2002). These traits are typical of the Nullarbor Plain sediments.

In the early 1990s, a series of sediment samples were taken from Koonalda Cave and from a nearby open rock shelter, named Allen's Cave (Cane, 1995; Roberts et al., 1995 and 1996). The latter has formed from a collapsed doline offering a modest overhang rather than a deep karst cave. Optical dating was performed on all samples from both sites but only those from Allen's Cave proved viable. The Koonalda Cave samples were found to suffer significant discrepancies between optical and calibrated ${ }^{14} \mathrm{C}$ dates when surface sediments were tested (Roberts et al., 1995 and 1996). It was stated that bleaching problems existed in water lain sediments transported deep into the cave and this could potentially overestimate the actual age;

"The result for Koonalda Cave demonstrates that luminescence dating methods are unsuitable for deposits in deep karst systems where episodic storage and intermittent transport of sediment in the darkness of the cave is apt to lead to an overestimate of the elapsed time since the deposit was last reworked" (Roberts et al., 1996:15).

Deep karst systems present particular difficulties for trapped charge based techniques when there is incomplete bleaching in antiquity. However, the dating for Allen's Cave did not suffer this phenomenon and did indeed extend human occupation of the Nullarbor region to circa 40,000 years (Roberts et al., 1996). This alone has added some weight to Gallus's original speculation of 30,000 years or more for Indigenous use of Koonalda Cave. 


\section{DISCUSSION}

Gallus argued for great antiquity of the site, convinced that human presence commenced at least 30,000 years ago. Whilst the single radiometric result of $31,500 \mathrm{BP}$ was within the range he anticipated, it appeared to work against his research effort due to the discordant stratigraphic location of this sample. Gallus himself acknowledged the inconsistent radiometric results, pointing out the three different formations at the intersection of the upper white and lower red horizons. He found it unsurprising then that the carbon dates contradicted:

“...stratigraphy cannot be judged from small sections alone, as details remain obscure and escape notice; no sweeping simplifications can be attempted..." (Gallus, 1973:8).

The problems for radiometric dating in Koonalda Cave have been much discussed over the intervening years (Gillespie, 2002 and Bednarik, 2007) and more broadly, the inherent issues of attempting chronology via typology have certainly been much discussed in archaeology (Renfrew and Bahn, 2016). The application of optical dating techniques as a more recent step in establishing a precise chronological framework for Koonalda has also been challenged by the nature of its very sediments: "...luminescence methods are unsuitable for deep cave sites where episodic storage and transport in darkness result in overestimation of the time since last exposure to sunlight" (Gillespie, 2002:7).

The need for reliable dating is critical to interpreting the parietal art and flint procurement that has enabled Koonalda to gain national heritage listing and international recognition. Reliable dating will also enable a better understanding of cave development over time, whilst better understanding of the nature of stream flow, development of the lakes and episodic roof collapse is critical to interpreting human response to a changing cave.

It has been speculated that the subterranean lakes in Koonalda offered a reliable and large source of water during the LGM (Smith, 2013). However, the lake in the north-west passage appears to have dried up in the LGM (Frank, 1971) and it is not known when the lakes in the north passage formed. The north passage is void of finger flutings and virtually void of flint activity, despite offering as much potential as the north-west passage. The north passage may have been inaccessible until such as time as Indigenous people were no longer involved in these activities. Equally, the north passage may have been accessible but avoided due to being a true dark zone unlike the main chamber (where the major flint quarrying has occurred) and the north-west passage (which contains the principal 'art gallery' area. Prior to massive roof fall resulting in the 'ramparts' separating the main chamber and the northwest passage, this area may have experienced more light than currently whereas the north passage has always been dark.

\section{CONCLUSION}

It is the significance of the art and the mining, the very cultural values that enabled Koonalda to gain National Heritage status, that are least understood due to the lack of credible and reliable dating of this site. It is crucial for the interpretation and context of these values that dating be achieved. Early attempts at establishing a concise and reliable chronology for Koonalda Cave applied typology, radiometric analysis and finally optical dating. Each have faced significant challenges that arose due to the very nature of deposition in deep karst systems.

Radiometric results currently offer a broad statement about the two distinct horizons and two significant finds: the dingo was well established on the Nullarbor Plain over 3,000 years ago; and Indigenous people had created parietal art by 18,000 years ago and were procuring flint throughout the LGM and into the early Holocene at least. Improved dating techniques are also vital for understanding human adaptation to an extremely arid zone possibly without access to reliable sources of subterranean aquifers, as hypothesised elsewhere (Cane, 2013 and Smith, 2013).

The introduction of improved single-grain dating techniques opens up the possibility of at least, disentangling the multiple events in sites such as Koonalda Cave where quartz grains are few and small. Techniques capable of reliably extracting the $1 \%$ or less quartz from the clays using aggressive floatation and decanting techniques, thus improving yields of quartz in the 100 to $200 \mu \mathrm{m}$ range are currently being modelled (McCulloch pers.comm, Research School of Earth Sciences, Australian National University, January 2017). It is hoped that a combination of procuring fresh in situ samples and applying improved single-grain dating techniques will prove successful in addressing the varied and vital issues discussed in this paper.

\section{REFERENCES}

Bednarik R, 1986. The parietal art of South Australia. Journal of the Anthropological Society South Australia 24(1): 3-21.

Bednarik R, Aslin GD and Bednarik E, 2003. The cave petroglyphs of Australia. Rock Art Research 3: 1-7.

Bednarik R, 2007. Rock Art Science, the Scientific Study of Palaeoart. New York, Aryan Books International.

Cane S, 1995. Nullarbor antiquity: archaeological, luminescent and seismic investigations on the Nullarbor Plain. Unpublished report to the National Estate Grants Program, Australian Heritage Commission, Department of State Aboriginal Affairs, Department of Environment and Natural Resources.

Cane S, 2013. First Footprints, the Epic Story of the First Australians. Allen \& Unwin, Australia.

Commonwealth of Australia, 2014. Koonalda Cave Heritage Listing. Fact Sheet produced by the Australian Government, Department of Environment.

Flood J, 1997. Rock Art of the Dreamtime. Sydney, Harper Collins.

Frank R, 1971. The Sediments. In Wright RVS, ed., Archaeology of the Gallus Site. Australian Institute of Aboriginal Studies, Canberra: $31-44$. 
Gallus A, nd. Field notebooks 1960-1972. Unregistered items, South Australian Museum Archives.

Gallus A, 1966. Preliminary report on the expedition to Koonalda Cave Dec 1965-Jan 1966. Unpublished report to Australian Institute Aboriginal Studies (64/44 Pt.1. [77A] 8924 A1, B5).

Gallus A, 1968a. Parietal Art in Koonalda Cave, Nullarbor Plain, South Australia. Helictite 6(3): 43-49.

Gallus A, 1968b. Archaeological Excavations at Koonalda, Nullabor Plain, 1957-67. Journal of the Anthropological Society South Australia 6(7): 4-8.

Gallus A, 1971. Results of the Exploration of Koonalda Cave, 1956-68. In Wright RVS, ed., Archaeology of the Gallus Site. Australian Institute of Aboriginal Studies, Canberra: 8-133.

Gallus A, 1973. Expedition to Koonalda Cave. Australian Institute of Aboriginal Studies, Canberra: 2.11.73 [Doc No. 73/1363 8324 pMs629].

Gillespie R, 2002. Dating the First Australians. Radiocarbon 44(2):455472.

Jennings JN, 1961. A preliminary report on the karst morphology of the Nullarbor Plains. Occasional Paper No.2 Cave Exploration Group South Australia: 27-28.

Lee Lyman R, 1994. Vertebrate Taphonomy. Cambridge, Cambridge Manuals in Archaeology.

Pretty GL, 1960. The CEG(SA) Nullarbor expedition 1959/60, Archaeological notes. Sydney University Speleological Society Journal VI:2-7.

Pretty G and Gallus A, 1967. The Anthropology and Archaeology of the Nullarbor Plain. In Dunkley JM and Wigley TML, eds., Caves of the Nullarbor, a review of speleological investigations in the Nullarbor Plain, Southern Australia'. Sydney University Speleological Society and Cave Exploration Group, South Australia: 47-50.

Renfrew C and Bahn P, 2016. Archaeology; Theories, Methods and Practice. USA, W.W. Norton \& Co.
Roberts RG, Spooner NA, Jones R, Cane S, Olley JM, Murray AS and Head MJ, 1995. Part 11; Luminescence dating of the archaeological sediments on the Nullarbor Plain, South Australia. In Cane S, ed., Nullarbor Antiquity: archaeological, luminescent and seismic investigations on the Nullarbor Plain. Department of Environment and Heritage: $57-72$.

Roberts RG, Spooner NA, Jones R, Cane S, Olley JM, Murray AS and Head MJ, 1996. Preliminary luminescence dates for archaeological sediments on the Nullarbor Plain, South Australia. Australian Archaeology 42:7-16.

Sharpe C and Sharpe K, 2003. The Boulder Engravings in the Upper Chamber of Koonalda Cave, South Australia. Web site: $<$ http://www.ksharpe.com/word/AR20.htm>. Accessed 2017 January 18.

Sharpe K, 2008. The Upper Chamber of Koonalda Cave, South Australia: its rockfalls, their weathering and use. Web site: $<$ http://www.ksharpe.com/word/AR23.htm>. Accessed 2017 January 18.

Sharpe K and Fawbert H, 2000. The smoothing and rounding of the boulders in the Upper Chamber of Koonalda Cave, South Australia. Web site: <http://www.ksharpe.com/word/AR01.htm>. Accessed 2017 January 18.

Smith B, (editor), 2015. The Dingo Debate, origins, behaviour and conservation. Victoria, Commonwealth Scientific Industrial Research Organisation.

Smith M, 2013. The Archaeology of Australia's Deserts. Cambridge University Press, Cambridge World of Archaeology.

Walshe K, 2012. Port Augusta hearth site dated to 40,000 years old. Australian Archaeology 74: 106-110.

Wright RVS, (editor), 1971. Archaeology of the Gallus Site. Canberra, Australian Institute of Aboriginal Studies.

Zlot R and Bosse M, 2014. Three-Dimensional mobile mapping of caves. Journal of Cave and Karst Studies 76(3): 191-206, DOI $10.4311 / 2012 \mathrm{EX} 0287$. 